\title{
Integrative Behavioral Couple Therapy is as effective as Traditional Behavioral Couple Therapy for distressed couples
}

Christensen A, Atkins DC, Berns S, et al. Traditional versus integrative behavioral couple therapy for significantly and chronically distressed married couples. J Consult Clin Psychol 2004;72:176-91.

\section{Q How does Integrative Behavioural Couple Therapy (IBCT) compare with Traditional Behavioural Couple Therapy (TBCT) for significantly and chronically distressed married couples?}

\section{METHODS}

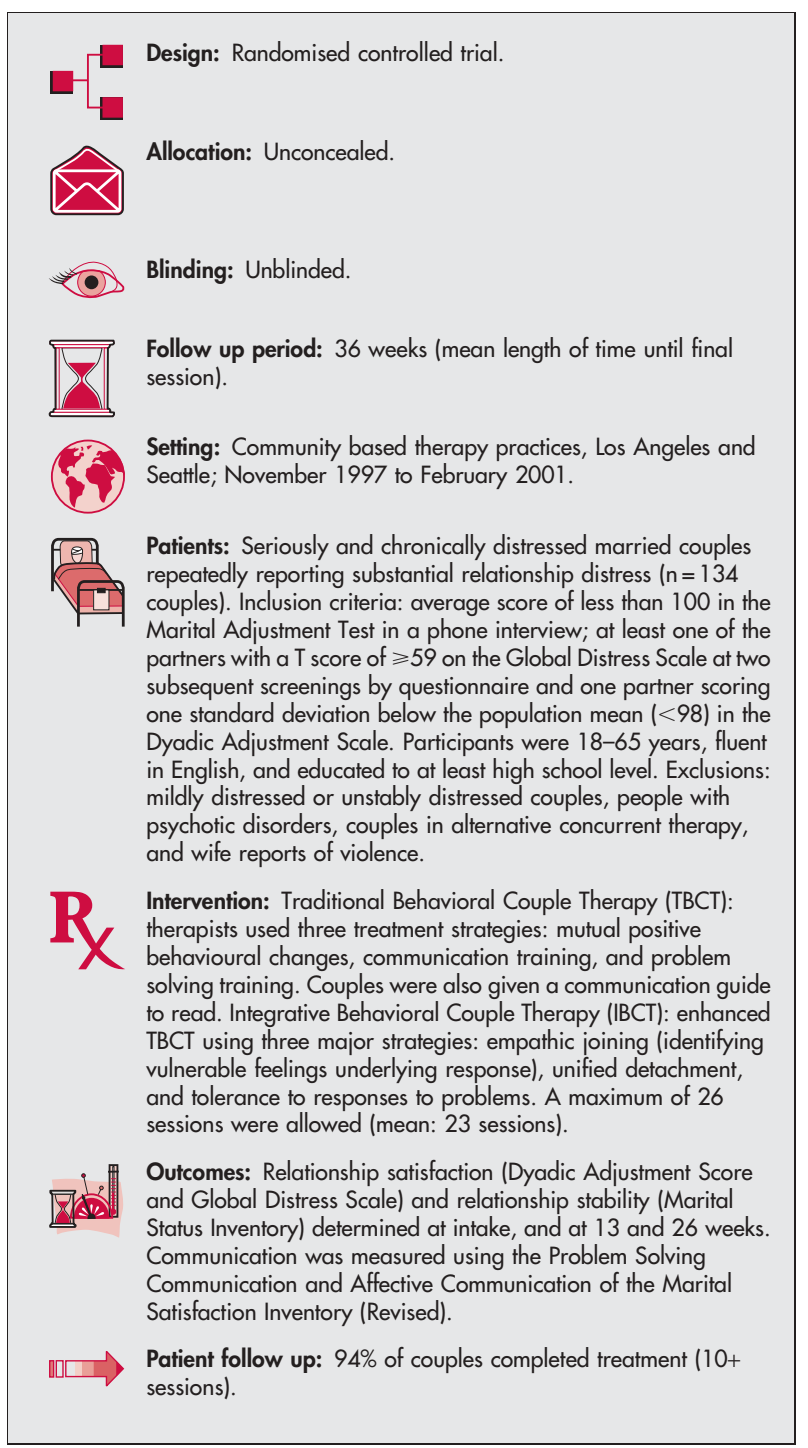

\section{MAIN RESULTS}

At final assessment, there was no significant difference between IBCT and TBCT $(\mathrm{p}=0.34)$ although both treatments resulted in

For correspondence: Andrew Christensen, Department of Psychology, University of California, Los Angeles, California, USA; christensen@ psych.ucla.edu

Sources of funding: the National Institute of Mental Health. clinically significant improvement $(71 \%$ of couples showed reliable improvement or recovery in IBCT $v 59 \%$ showing improvement in TBCT).

\section{CONCLUSIONS}

TBCT and IBCT are equally effective for distressed couples. Marital therapy is associated with significant change over time in relationship satisfaction, stability, and communication.

\section{Commentary}

Trigr his exceptionally rigorous and well designed study is likely to have a significant impact upon the field of behavioural couple research and therapy because it represents a movement away from a primary focus on skills training to examining more emotional dyadic issues. Similarly, research on issues such as relationship cognitions ${ }^{1}$ and attachment styles ${ }^{2}$ both have indicated that the ways in which couples cognitively process their interactions have substantial impact on immediate interactions and on their global perceptions of their relationships. Findings from more psychodynamic interventions such as insight oriented marital therapy ${ }^{3}$ and emotion focused couple therapy ${ }^{4}$ also have indicated that interventions targeted toward increasing partners' understanding of one another and emotional connection appear to have great and potentially lasting impact on the couple's functioning.

This new study on IBCT fits nicely into this accumulating literature and provides greater impetus in the movement toward integrating emotional and cognitive factors into couple treatments. Indeed, these results suggest that after taking time to help partners understand each other's positions on the problems and to develop mutual empathy with, and tolerance of, each other's struggles, problems may resolve and/or decrease in importance, so problem solving skills, when needed, may be put to more effective use. Rather than encouraging couples to parrot the new rules or "skills" without addressing the cognitive and emotional contexts of previously problematic behaviours, the acceptance interventions create a new empathic emotional atmosphere and shared understanding of the problem's context that automatically promotes change with less need for new skills. It is this importance placed on "contingency shaped" changes rather than rule governed changes that is most eye opening for me.

Finally, the effort to guarantee that these interventions were tested on truly distressed couples ensures that these findings are likely to generalise to most clinic couples. However, the exclusion of the criteria of alcohol abuse and borderline personality disorder does suggest that clinicians should be cautious when extending these results to couples in which these issues are present. Still, overall, this excellent study provides couple therapists with much needed tools to use with couples stuck in seemingly insurmountable and unchangeable distress.

Kristina Coop Gordon, PhD University of Tennessee, Knoxville, TN, USA

1 Baucom DH, Epstein N, Daiuto AD, et al. Cognitions in marriage: the relationship between standards and attributions. J Fam Psychology 1996;10:209-22.

2 Johnson SM, Whiffen VE. Attachment processes in couple and family therapy. New York: Guilford Press, 2003.

3 Snyder DK, Wills RM, Grady-Fletcher A. Long-term effectiveness of behavioral versus insight-oriented marital therapy: a four year follow-up study. J Consult Clin Psychology 1991:59:138-41.

4 Johnson SM, Greenberg LS. Differential effects of experiential and problemsolving interventions in resolving marital conflict. J Consult Clin Psychology 1985;53:175-84 